\title{
EFFECT OF WETTABILITY ON ICE ADHESION OF METAL SUBSTRATE
}

\author{
Simona IVANOVÁ, Věra SOUKUPOVÁ, Viktorie WEISS, Martina PAZDEROVÁ \\ Czech Aerospace Research Centre, Prague, Czech Republic, EU, \\ ivanova@vzlu.cz, soukupova@vzlu.cz,weiss@vzlu.cz, pazderova@vzlu.cz
}

https://doi.org/10.37904/metal.2019.882

\begin{abstract}
The issue of anti-frost surface treatment is a current research topic, especially in the transport and energy industries. Ice and its formation, adhesion and accumulation can cause serious problems on the surface of wind turbines, solar panels, power lines, roadways, in aircraft industry as in everyday life. These aspects can reduce energy production efficiency, increase energy consumption, cause mechanical or electrical failure, and increase security risks. This article deals with the wettability of surface treatment and its influence on the formation of icing on metal surfaces. In this study, new method for fabricating anti-icing coating was employed. The metal samples were first surface treated and afterwards the anti-icing coating for titanium alloy samples was applied and coating properties were examined. Various surface treatment steps were tested for the coating anti-icing properties. The formation of icing was experimentally tested on modified surface of metal substrates. Wetting properties of the titanium surface was evaluated by contact (wetting) angle measurements. The surface structure of the metal samples was examined by SEM (Scanning electron microscopy). Testing of anti-icing properties of the surface treatment took place indoors. Physical and mechanical properties of the samples were evaluated before and also after the testing at low temperature.
\end{abstract}

Keywords: Coatings, Surface, Icing, Anti-acing coatings, Hydrophobicity, Contact angle

\section{INTRODUCTION}

Icing is a phenomenon that occurs on the surface of objects under specific climatological conditions. Currently, there are active and passive approaches. Anti-freeze surfaces are defined as icing-resistant surfaces in a passive approach. They repel icing on the surfaces. For example, highly hydrophobic materials are representative of passive approach and application of these materials is currently intensively investigated. On the other hand, the active approach uses various technological processes, such as heating based on the principle of resistance heating, for release of frost [1,2]. This issue has started the development of so-called ice-phobic/antifreeze surfaces. The definition of anti-freeze surfaces is not uniform and differs in the literature. Some sources define icephobicity as a low adhesion force between the ice formed and the solid surface, or just a reduction of normal adhesion properties. Other expert sources characterize antifreeze surfaces as the ones with abillity to reduce or prevent ice formation [3-7]. The terms hydrophobicity and hydrophilicity are often used to describe the wetting of a solid surface when the liquid is water. The shape of the water droplet and its behaviour on the surface of a solid material determines whether the material is hydrophobic or not. The shape of the drop is characterized by the angle that forms the tangent to the surface of the water droplet at the solidliquid-gas interface. This angle is called the contact angle $\theta$. Two cases may occur after the application of small amount of water to a perfectly smooth surface. The first case is called hydrophobicity and the second case is hydrophilicity (for contact angle $<90^{\circ}$ ). Ultrahydrophobicity is a case of poor wetting of the surface by water $\left(\theta>150^{\circ}\right)$. The water does not wet perfectly under these conditions. Superhydrophobic surfaces are usually characterized, when the contact angle is $120^{\circ}$ or more. These surfaces have characteristic features common with superhydrophobic surfaces. Surface deformations significantly affect wetting of the liquid [8-10]. In this work, the formation and adhesion of icing were experimentally tested on pre-surfaces modified titanium alloy samples (6061). The Samples with different coating were prepared to provide a different sample surface structure. 


\section{EXPERIMENTAL}

\subsection{Coatings preparation}

Titanium alloy (6Al4V) plates $(50 \times 50 \times 1 \mathrm{~mm})$, were used as substrates. The metal samples were degreased in an alkaline solution with addition of surfactant in ultrasound and then rinsed in demineralized water and dried with hot air. In this work, several structured coatings with different hydrophobicity on titanium substrate were prepared. The coatings were prepared by multiple stage process, including anodization, modification and passivation procedures. Technological process of samples preparation is shown in Table 1.

\section{Anodization process}

The anodization process was included in the samples to form a nanostructured surface. The times in both the modification and the passivation sections were varied to obtain a different surface texture of the titanium samples. The anodization process was carried out at ambient temperature with voltage close to $20 \mathrm{~V}$. The time of this process was 30 minutes. A nanostructured surface was created by this process on the samples.

Modification

A water bath with the addition of fluorinated dispersion was used for this step. The modification time was from 40 minutes to 1 hour and the temperature ranging around $60^{\circ} \mathrm{C}$.

Heat treatment

Some of the samples were heat treated. The temperature was between 70 and 90 degrees Celsius and time varied between 2 to 6 hours.

Passivation

The passivation process was carried out in an alcoholic solution of two carboxylic acids in ratio 7:1. The passivation time was about 1 hour and at temperature range from 30 to $35^{\circ} \mathrm{C}$.

Table 1 Coatings preparation of the samples used in this work

\begin{tabular}{|c|c|c|c|c|}
\hline Sample & Anodization process & Modification & Firing & Passivation \\
\hline $\mathrm{A}$ & - & 40 minutes & $70{ }^{\circ} \mathrm{C}, 2$ hours & - \\
\hline $\mathrm{B}$ & - & 40 minutes & $90^{\circ} \mathrm{C}, 2$ hours & - \\
\hline $\mathrm{C}$ & nanostructured surface & 40 minutes & $90^{\circ} \mathrm{C}, 2$ hours & - \\
\hline $\mathrm{D}$ & nanostructured surface & - & - & - \\
\hline E & nanostructured surface & - & & 1 hour \\
\hline $\mathrm{F}$ & - & - & - & 1 hour \\
\hline G & - & - & - & 1 hour \\
\hline $\mathrm{H}$ & - & - & $90^{\circ} \mathrm{C}, 2$ hours & 1 hour \\
\hline 1 & - & 1 hour & $90{ }^{\circ} \mathrm{C}, 2$ hours & 1 hour \\
\hline
\end{tabular}

\subsection{Contact angle measurements}

The method of measuring contact angles can be used as a quantifier to determine the hydrophobicity/hydrophilicity of a surface or surface treatment on a substrate. Contact angles were measured by using Theta optical tensiometer (Attension, Biolin Scientific) equipped with a high speed camera. The typical 
droplet size used for this measurement is between 1 and $10 \mu$ because of minimizing the gravity effect. Contact angles have been measured for demineralized water. The drop size of water was $2 \mu$ l. Principe of Sessile drop was using for optical contact angle measurement. The obtained contact angle values are summarized in Figure 1. Contact angle values slightly decreased for most samples after icing testing.

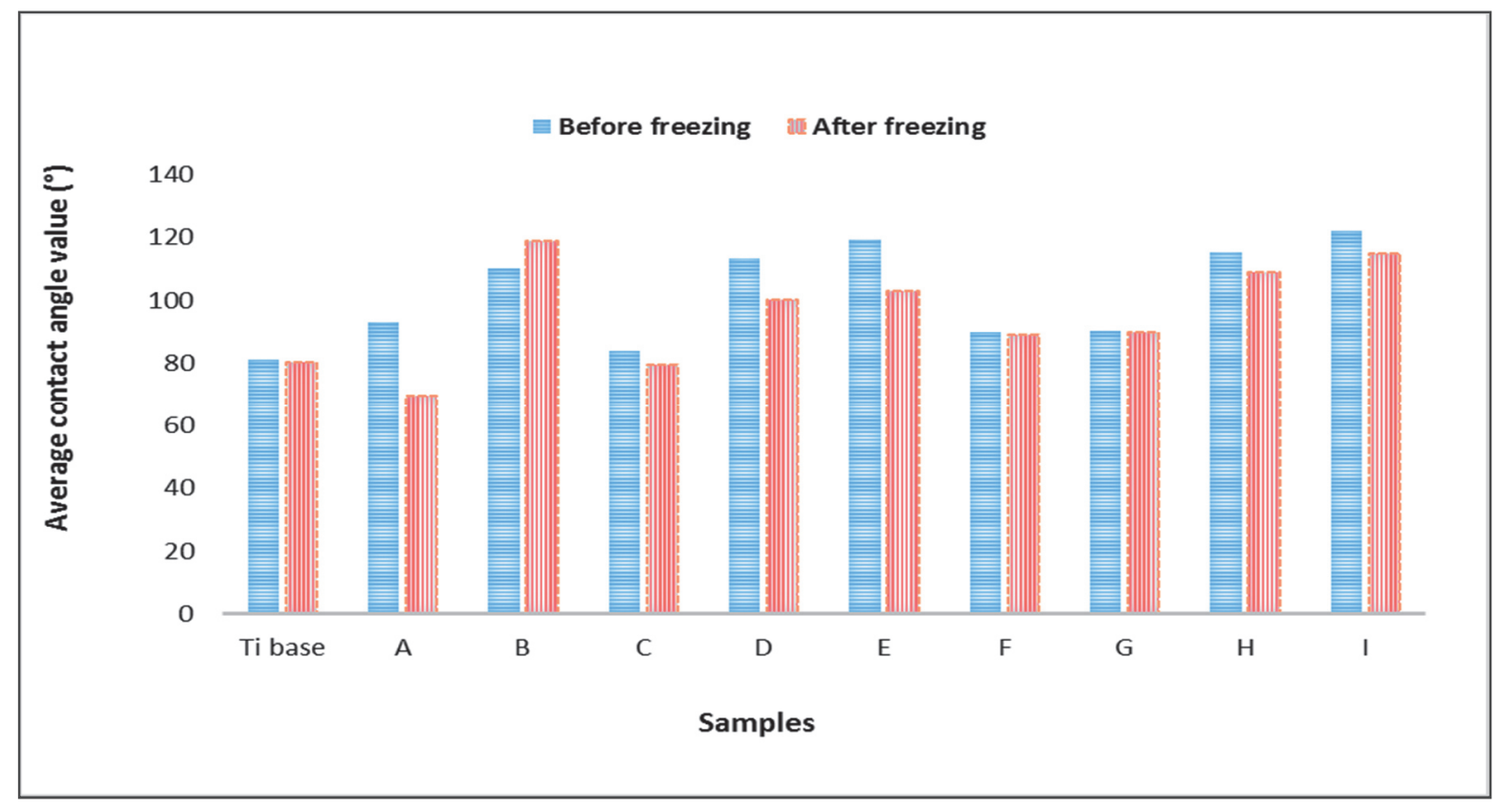

Figure 1 Contact Angle of samples with coating before and after freezing

\subsection{Layer roughness measurement}

Roughness measurement was performed by digital roughness meter DR 130. A total of three measurements were made on each sample. The measured average roughness values are shown in Figure 2. Comparable roughness values $(\mathrm{Ra})$ were obtained on the surface of treated samples.

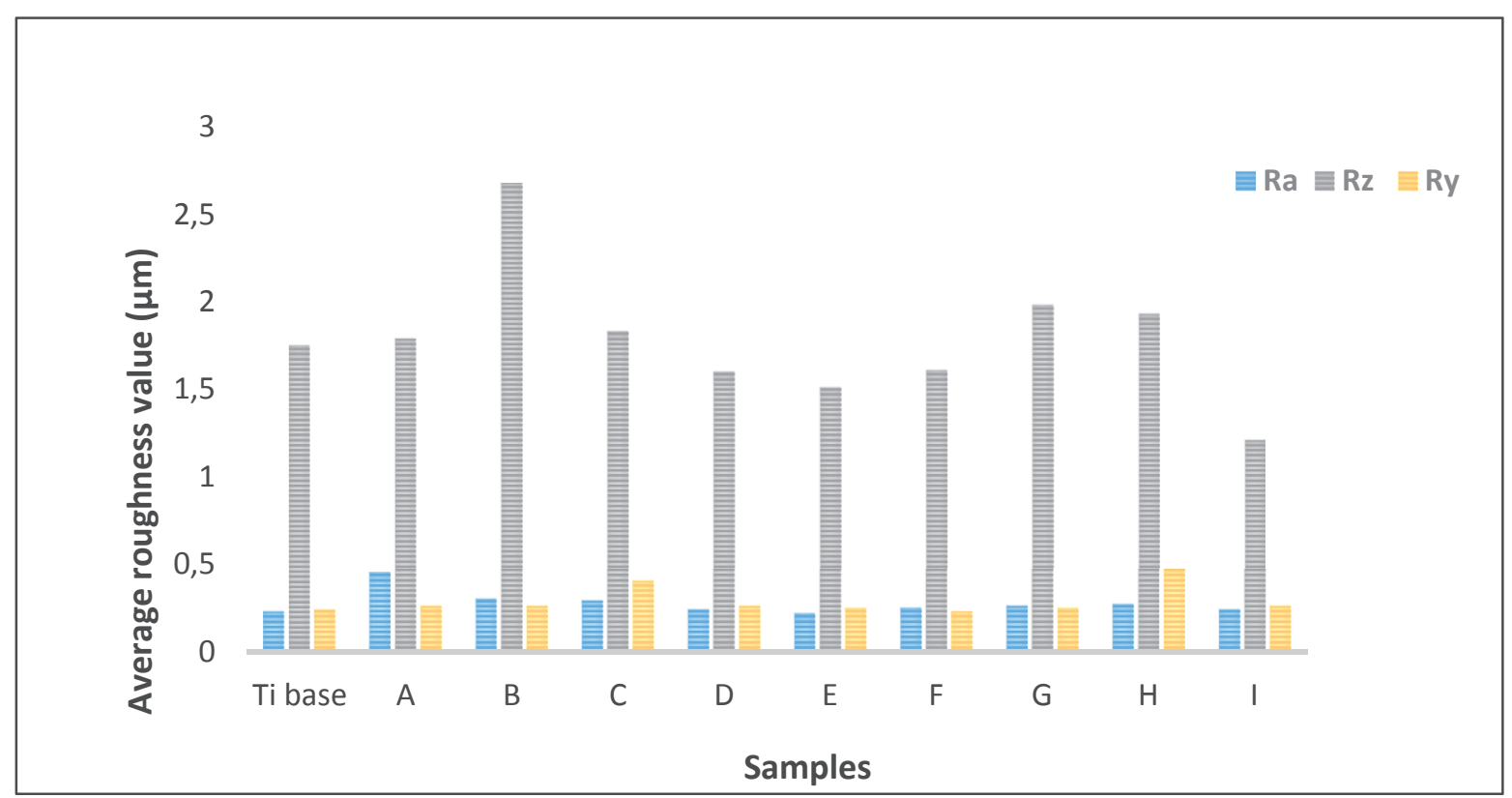

Figure 2 Roughness of samples with coating 


\subsection{Surface analysis by scanning electron microscopy (SEM)}

The structure of the deposited coating was examined by scanning electron microscopy (Vega 3, Tescan). The nanostructured surface and non-nanostructured surface are shown in Figure 3.
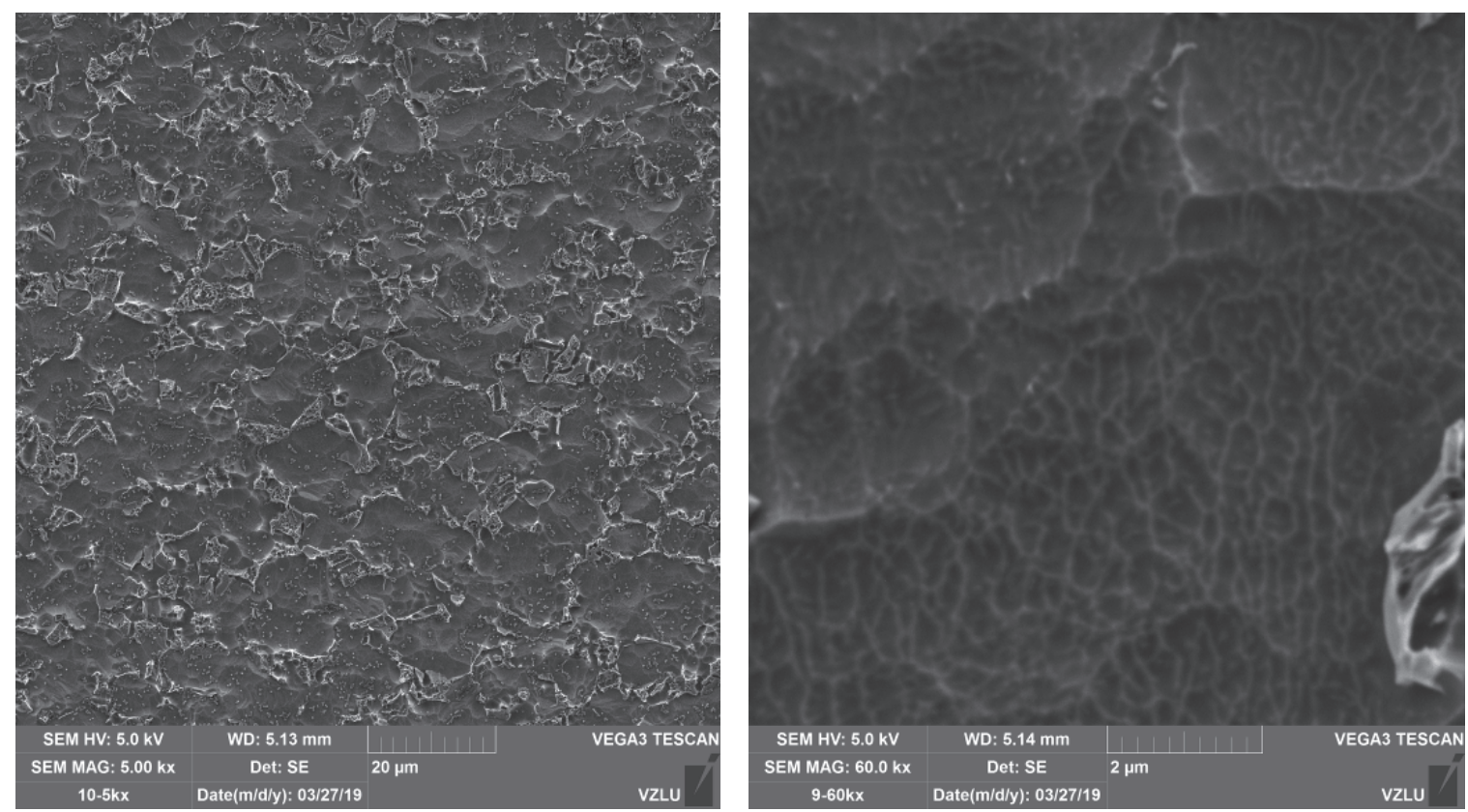

Sample without nanostructure (sample B)
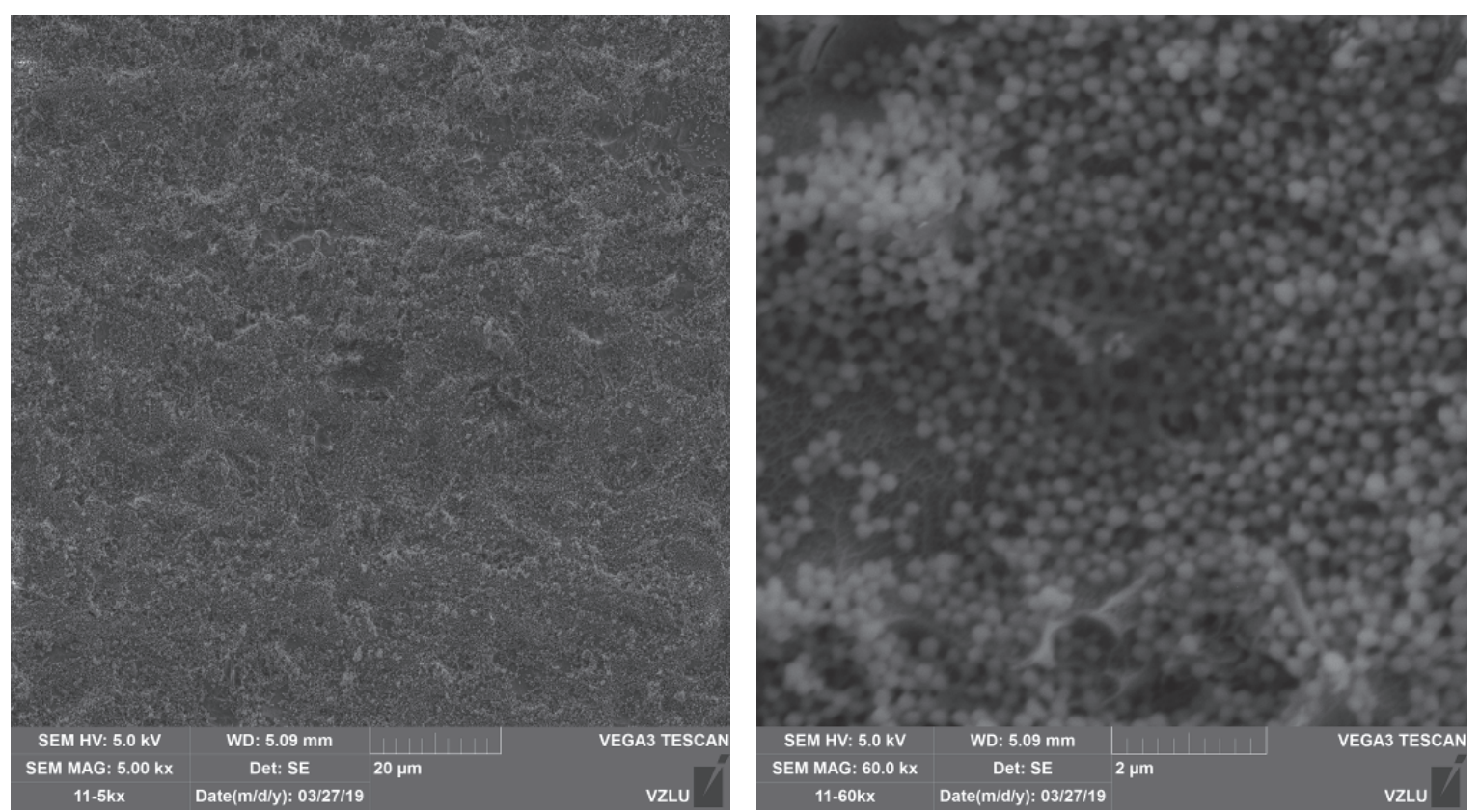

Sample with nanostructure (sample D)

Figure 3 SEM images of texture of surfaces with coatings

\subsection{Anti-icing coating testing}

Prepared samples with different coating were placed horizontally in the freezer. The testing of coating took for 5 days at temperature $-17^{\circ} \mathrm{C}$. Photographic documentation of the experiment is shown in Figure 4. 


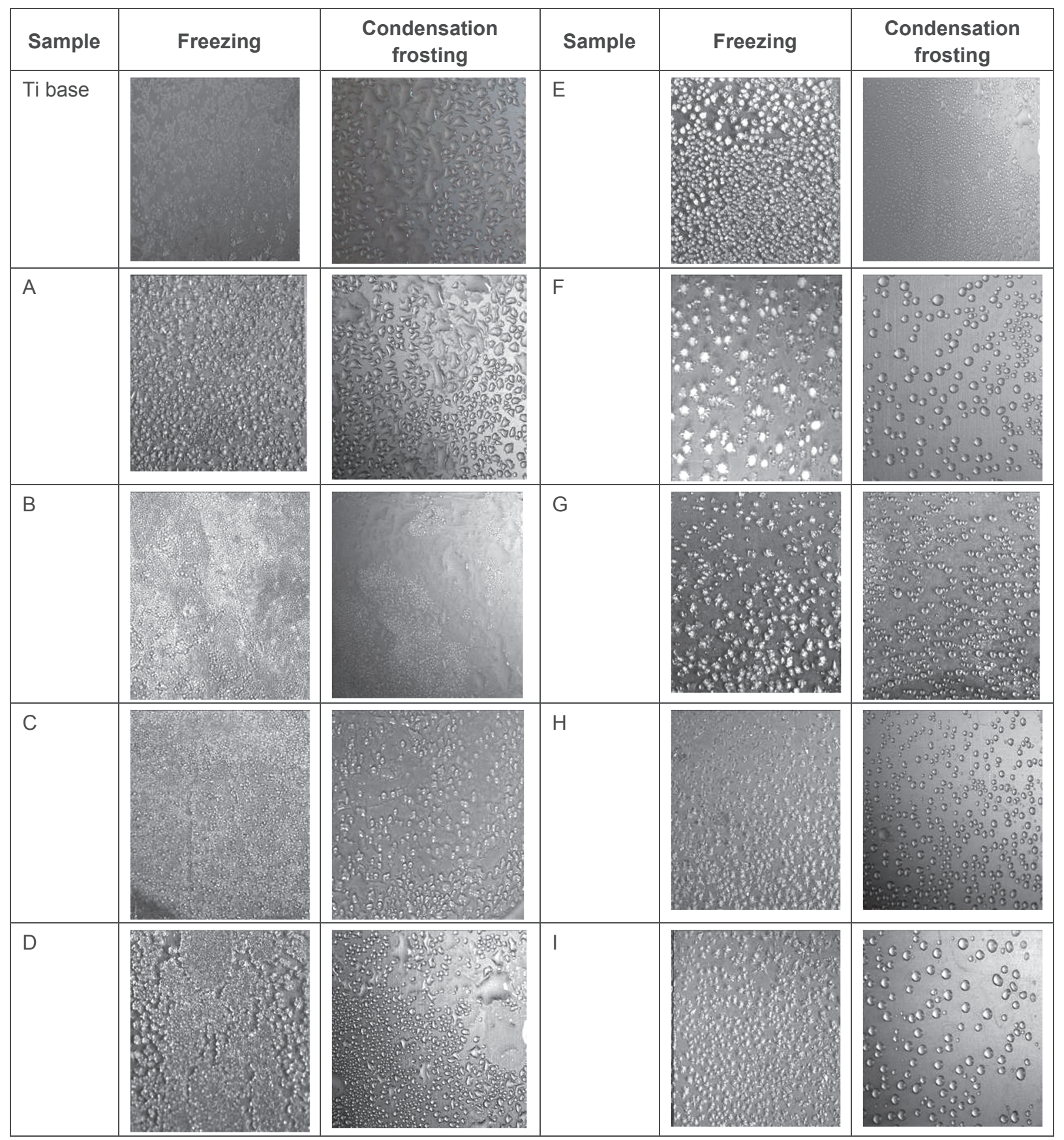

Figure 4 Photographic documentation of testing anti-icing coating

Ice crystals were formed separately on almost all samples, except for samples A, B and D. On these samples, the frost was a solid surface. Nanostructured texture of coatings on selected samples did not significantly improve anti-icing properties. The more obvious differences between coatings were seen during the condensation frosting at room temperature.

\section{CONCLUSION}

In summary, titanium samples with different coatings were fabricated by multiple step process including anodization, modification and passivation procedures. The different surface treatment of the samples ensured different surface texture of the samples and the wettability of the surfaces were affected. Superhydrophobicity 
was obtained on the surface with and without nanostructure. The obtained roughness values were not significantly different, the greater difference was in the values per sample. Contact angle measurements were performed before and after ice testing. This fact is mainly due to the multi-step process of coating deposition. The formation and adhesion of frost on prepared samples was experimentally tested in the freezer for five days. Icing was produced on all samples. In controlled freezing, differences in icing formation were primarily in the form of ice germs and the size of the affected area. The best results were achieved on samples where highest contact angle values were measured. Crystals were formed locally on these samples and had a spherical character. On the other specimens, a locally continuous frost was formed. These places were merged during melting. Crystals were not combined on the superhydrophobic samples and the dry places were retained. Simplifying coating deposition could help to uniform surface and reduce the number of icing initiation centers. The formation of icing and its adhesion is mainly influenced by the wettability of the surface and its structure. The right combination of two physical factors could be a solution to eliminate icing products.

\section{ACKNOWLEDGEMENTS}

\section{This project result was developed within the institutional support of the Ministry of Industry and Trade of the CR directed to the development of research organizations.}

\section{REFERENCES}

[1] GOHARDANI, Omid. The Exploration of Icephobic Materials and Their Future Prospects in Aircraft Icing Applications. J Aeronaut Aerospace Eng. 2012. 1:e116. DOI:10.4172/2168-9792.1000e116.

[2] SUSOFF, Markus, SIEGMANN, Konstantin, PFAFFENROTH, Cornelia, HIRAYAMA, Martina. Evaluation of icephobic coatings - Screening of different coatings and influence of roughness. Applied Surface Science [online]. 2013. vol. 282, pp. 870-879 [viewed 2019-03-15]. Available from: DOI: 10.1016/j.apsusc.2013.06.073.

[3] SOJOUDI, H., M. WANG, N. D. BOSCHER, G. H. MCKINLEY a K. K. GLEASON. Durable and scalable icephobic surfaces: similarities and distinctions from superhydrophobic surfaces. Soft Matter [online]. 2016. vol. 12, iss. 7 , pp. 1938-1963 [viewed 2019-03-15]. Available from: 10.1039/C5SM02295A

[4] STAMATOPOULOS, Christos, HEMRLE, Jaroslav, WANG, Danhong and POULIKAKOS, Danos. Exceptional Anti-Icing Performance of Self-Impregnating Slippery Surfaces. ACS Applied Materials \& Interfaces [online]. 2017. vol. 9, iss. 11, pp. 10233-10242 [viewed 2019-04-11]. DOI: 10.1021/acsami.7b00186. Available from: DOI: 10.1021/acsami.7b00186.

[5] GOLOVIN, Kevin, KOBAKU, Sai P. R., LEE, Duck H., DILORETO, Edward T., MABRY, Joseph M and TUTEJA, Anish. Designing durable icephobic surfaces. Science Advances [online]. 2016. vol. 2, iss.3 [viewed 2019-04-03]. Available from: DOI 10.1126/sciadv.1501496.

[6] SOJOUDI, H., M. WANG, N. D. BOSCHER, G. H. MCKINLEY a K. K. GLEASON. Durable and scalable icephobic surfaces: similarities and distinctions from superhydrophobic surfaces. Soft Matter [online]. 2016. vol. 12, iss. 7 , pp. 1938-1963 [cit. 2018-12-03]. Available from: DOI 10.1039/C5SM02295A

[7] BARTOVSKÁ, Lidmila, ŠIŠKOVÁ M. Fyzikální chemie povrchů a koloidních soustav. 6 rd ed. Praha: Vydavatelství VŠCHT, 2010, 262 s. ISBN 978-80-7080-745-3.

[8] GUO, Z., LIU, W. Biomimic from the superhydrophobic plant leaves in nature. Plant science. 2007. pp. 11031112.

[9] KEDROŇOVÁ, Eva. Vytváření nanostrukturních ultrahydrofobních vrstev pomocí plazmových trysek. Diplomová práce. Brno:Masarykova univerzita. 2010.

[10] NOSONOVSKY M., BHUSHAN. B., Superhydrophobic surfaces and emerging applications: Non-adhesion, energy, green engineering. Current Opinion in Colloid \& Interface Science. 2009. vol. 14, no. 4, pp. 270-280 [viewed 2018-12-20]. Available from: DOI: 10.1016/j.cocis.2009.05.004. 